\begin{tabular}{|c|c|}
\hline 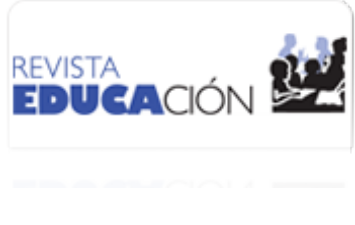 & $\begin{array}{l}\text { Revista Educación } \\
\text { ISSN: 0379-7082 } \\
\text { ISSN: } 2215-2644 \\
\text { revedu@gmail.com } \\
\text { Universidad de Costa Rica } \\
\text { Costa Rica }\end{array}$ \\
\hline
\end{tabular}

\title{
La evaluación anacrónica desde la docencia universitaria
}

Robles-Barrantes, Andrés Ariel

La evaluación anacrónica desde la docencia universitaria

Revista Educación, vol. 44, núm. 1, 2020

Universidad de Costa Rica, Costa Rica

Disponible en: http://www.redalyc.org/articulo.oa?id=44062009

DOI: https://doi.org/10.15517/revedu.v44i1.36367

Esta obra está bajo una Licencia Creative Commons Atribución-NoComercial-SinDerivar 3.0 Internacional. 


\section{La evaluación anacrónica desde la docencia universitaria}

Outdated Assessments from a University Teaching Perspective

Andrés Ariel Robles-Barrantes

Universidad Nacional, Costa Rica

DOI: https://doi.org/10.15517/revedu.v44i1.36367

andres.robles.barrantes@una.cr

(D) http://orcid.org/0000-0001-6298-4509

Redalyc: http://www.redalyc.org/articulo.oa?id=44062009

Recepción: 22 Abril 2019

Aprobación: 20 Agosto 2019

\section{Resumen:}

La evaluación dentro de las universidades como herramienta de medición se mantiene estática en el tiempo, sin recibir transformaciones. El objetivo del presente ensayo académico consiste en efectuar una fotografía de la dinámica docente enfatizando en la esencia de la evaluación y la docencia. Teniendo en cuenta que la docencia universitaria está llamada a ir más allá de las dinámicas tradicionales, cuya esencia se centra en la búsqueda constante por ser un espacio de construcción del conocimiento, uno que no puede reducirse simplemente a las reglas del mercado y sus directrices económicas, sino que tiene la obligación de centrarse en función de la persona concluyendo en la importancia de la reflexión crítica para alejarse de un sistema en donde cada vez hay menos creatividad, menos construcción del pensamiento y que en su lugar se fortalece la replicación de conocimientos, la repetición simultánea, la memorización de información y la frívola medición numérica.

Palabras Clave: Docencia, Universidad, Evaluación, Educación.

\section{Abstract:}

Academic assessments have always been used by universities to gauge student learning. Yet, they have remained unchanged through time. The objective of this essay is to take a snapshot of current teaching and assessment practices. It is the essence of today's university teaching staff to go far and beyond their traditional duty and continuously challenging their students to seek learning experiences outside of the classroom. Concepts taught by professors and lecturers should not only be based on market regulations and economic guidelines. They have the duty to focus on the individual and promote critical thinking in a world that is less creative and thought-driven and more focused on replication of knowledge, simultaneous repetition, rote memorization of information and frivolous numerical measurements.

KEYWORDS: Teaching, University, Evaluation, Education.

\section{UNA MIRADA GENERAL A LA DOCENCIA UNIVERSITARIA}

Si se observa la fotografía de un aula universitaria de Costa Rica hace más de 50 años y se compara con una de un aula del hoy, es posible encontrar que siguen siendo altamente similares, posiblemente iguales. Ambas regidas por la misma forma de acomodar sus mesas y sus sillas. Su organización espacial no ha variado a pesar de las recomendaciones que puedan existir para que cuenten con estructuras y acomodos cuyo fin sea contribuir con el proceso de enseñanza. Las imágenes no solo hablan de la no evolución en cuanto a la estructura de los salones de clase, sino que irónicamente, y también tristemente, reflejan de forma material el no avance de dinámica pedagógica dentro de la universidad latinoamericana.

La docencia universitaria está llamada a ir más allá, a ser la herramienta de construcción del conocimiento, a ser el camino de transformación del pensamiento en pro de una contribución permanente a la sociedad. No debe ser una réplica de recetas, un apéndice más del sistema educativo que rige un territorio, no debe ser una repetición de los errores de otros espacios educativos. Es decir, es un espacio diferente a los procesos de primaria y secundaria. ¿Realmente esto sucede dentro de nuestras aulas? Sería el cuestionamiento que es necesario desarrollar y reflexionar como docentes universitarios, partícipes activos en el proceso pedagógico, 
siendo las personas encargadas directamente del ejercicio de la docencia. Desafortunadamente, la docencia universitaria que paulatinamente ha replicado muchas de las prácticas que se ejecutan en otros niveles de la formación educativa a pesar de las fuertes críticas que se lanzan desde el pedestal universitario hacia sus procesos antecesores. Esos niveles en donde es posible detectar las falencias que luego son replicadas por las mismas personas docentes que las critican. Un ciclo de comportamientos que son legitimados por el sistema imperante, espacio donde se limita cada vez más las capacidades analíticas de las personas, el pensamiento crítico, la investigación, el razonamiento, la extensión. Kaplan (2000) describe que

(...) la universidad debe tender a ser de y para todos, y no de y para élites privilegiadas y grupos dominantes. No debe reducirse a la impartición de un conocimiento puramente teórico y contemplativo, a la revelación de verdades eternas, ni al mantenimiento del status quo como valor en sí mismo (p.104).

Sin embargo, la tendencia de un sistema en donde cada vez hay menos creatividad, menos construcción del conocimiento, y en su lugar se fortalece la replicación de información, la repetición, la memorización y la frívola medición numérica, es cada vez más imperante.

¿Será que la foto de la práctica docente, especialmente de las formas en que se evalúa, en la actualidad sería diferente a la desarrollada por docentes hace más de 50 años? ¿Será que el comportamiento de las personas docentes es similar debido a implicaciones políticas del sistema? ¿Aún se evalúa y facilita procedimientos de la misma forma? Estas son muchas de las consultas que sería necesario analizar para conocer las implicaciones del desempeño docente y su aporte en el aula universitaria.

Dando especial énfasis a la evaluación dentro de los procesos pedagógicos debido a que ha tomado un papel trascendental en la realidad que se vive diariamente en los procesos universitarios. La evaluación entendida como un proceso de medición, como plantea Mora (2004),

(...) la evaluación se puede entender de diversas maneras, dependiendo de las necesidades, propósitos u objetivos de la institución educativa, tales como: el control y la medición, el enjuiciamiento de la validez del objetivo, la rendición de cuentas, por citar algunos propósitos (p.2).

Las preguntas aquí lanzadas son contempladas como el eje fundamental, abierto al debate, que este ensayo académico plantea en fiel convencimiento de que la crítica y la autocrítica abre espacio a la construcción y reinvención necesaria en todo proceso dialéctico.

\section{Evaluación DESDE LAS AULAS UNIVERSITARIAS}

La docencia universitaria debe trascender los paradigmas de formación establecidos en la estructura educativa de todos los niveles que le anteceden. Esto implica una concepción del proceso pedagógico abordada desde otras perspectivas y relaciones entre los actores envueltos. Dentro de una concepción tradicional de la formación educativa se ha entendido a la evaluación como uno de los ejes de mayor importancia dentro del proceso formativo. Sánchez (2013) plantea que la evaluación:

(...) la evaluación ha hecho presencia -mediante una amplia red de prácticas que de múltiples y sutiles formas determinan sendas diferenciaciones entre la anormalidad y la normalidad- entre los aceptados y los rechazados, entre los buenos y los malos, entre la inclusión y la exclusión, entre aptos e ineptos, entre lo que sirve y lo que no sirve, entre lo que se debe aceptar y lo que se debe rechazar. (p.757)

En muchos casos la evaluación ha llegado a ser el elemento de mayor énfasis dentro del proceso educativo, la cual sin lugar a dudas tiene grandes implicaciones sociales.

La forma de evaluación tradicional ha recaído sistemáticamente en manos de la persona docente encargada del proceso pedagógico. En el caso particular de cursos universitarios la evaluación envuelve, en la mayoría de los casos, diferentes criterios caracterizados por enfoques cuantitativos que responden a lo que el personal docente considera se debe evaluar. Surge entonces la subjetividad evaluativa como herramienta de medición 
de los procesos, específicamente cuando es la persona docente quien define los contenidos que evalúa, la forma que lo hace y el tiempo con que se hace, al mismo tiempo estas mediciones surgen como herramientas para la definición de subjetividades en los estudiantes. Nuevamente Sánchez (2013) indica en esta misma línea que "la subjetividad se refiere al análisis de los modos en que la evaluación educativa opera sobre los sometidos (individuos o colectividades), para fabricarlos, moldearlos, manipularlos, agenciarlos, controlarlos, regularlos, seleccionarlos, excluirlos o promoverlos" (p.758). Lo mismo sucede en el momento de revisión de las evaluaciones, nuevamente la subjetividad juega un papel en la interpretación de las respuestas y su consideración como acertadas o erradas de acuerdo a parámetros previamente establecidos. Se convierte además en parte del proceso de la imposición, característica común dentro de las aulas universitarias. En esta línea, Freire (1987) establece que los docentes:

(...) dictamos ideas. No cambiamos ideas. Dictamos clases. No debatimos o discutimos temas. Trabajamos sobre el educando. No trabajamos con él. Le imponemos un orden que él no comparte, al cual solo se acomoda. No le ofrecemos medios para pensar auténticamente, porque al recibir las fórmulas dadas simplemente las guarda. (p.93)

Bajo ese mismo planteamiento, es posible considerar las formas de evaluación utilizadas mayoritariamente dentro de la universidad como parte de la imposición sistemática.

El quehacer docente que muchas veces se ve permeado por procesos formativos que terminan reduciéndose a la aplicación de evaluaciones. Es posible identificar casos las mismas no se encuentran en función del proceso de aprendizaje de los estudiantes, sino más bien en perjuicio de estos, incluso muchas responden en las facilidades para los docentes y no necesariamente las implicaciones en el estudiantado. Mejía (2012) describe que:

(...) la evaluación se revela como una mera probación del poder del profesor contra la libertad de los alumnos, y ejerce una medida de control disciplinario tanto a la imposición docente como a lo que el profesor espera que el alumno conteste en las pruebas escritas y, en general, a lo que debe saber: lo deseable por el profesor más que por el currículo en sí. (p.30)

Se vuelve notorio, además, las formas de evaluación delimitadas a procesos donde se ejercita simplemente la memoria. Donde las personas estudiantes están en la obligación de repetir los conocimientos dados por la persona docente y los cuales son los únicos valorados como verdades. Un ejercicio de repetición. Antes de profundizar en los detalles a los que responde la evaluación es necesario hacer un análisis sobre el rol político que desempeña la educación formal. La educación no puede abordarse de otra forma que no sea entendiendo su naturaleza política. En esa línea Freire (1985) plantea que:

La educación, sea en la universidad, la escuela secundaria, la primaria o en la alfabetización de adultos, es un acto político. ¿Por qué? Porque la naturaleza misma de la educación tiene las cualidades inherentes para ser política, así como la política posee aspectos educativos. En otras palabras, un acto educativo tiene naturaleza política, y un acto político tiene naturaleza educativa (pp.184-185).

Sus implicaciones y repercusiones en la sociedad, así como se desenvuelve a partir de influencias y decisiones de diferentes actores sociales. Comprender su naturaleza política puede contribuir en la forma que las personas docentes racionalizan su desempeño y la forma en que actúan dentro de las aulas universitarias.

\section{EL ROL POLÍTICO DE LA EVALUACIÓN ANACRÓNICA COMO LEGITIMACIÓN DEL SISTEMA}

Partiendo de un análisis regional, la imposición se vuelve una de las herramientas neoliberales más recurridas en las últimas tres décadas en Latinoamérica. Cancino (2010) plantea que "podemos entender que la reorganización neoliberal de los sistemas económicos en América se proyectó al campo de la cultura, de la educación, y en especial a las universidades las que fueron sometidas a los dictados del mercado" (p.152). Es decir, la universidad latinoamericana se encuentra en una realidad compleja donde un sistema económico ha impuesto las reglas en las que debe regirse. 
Dentro de este contexto la masificación, planteada como un adormecimiento del razonamiento crítico, encontró su escudo en los programas de las asignaturas, reducidos a proyecciones estándar en las cuales el cuerpo docente de todos los niveles está sujeto por obligación a su cumplimiento. En muchas ocasiones recurriendo incluso a la imposición metodológica, lo cual deja aún más delimitada la ya desdeñada labor docente. ¿Aún evaluamos y facilitamos procedimientos de la misma forma que hace varias décadas? Es una pregunta necesaria para contemplar las implicaciones sociales y políticas que tiene la evaluación educativa. Este proceso educativo donde la evaluación tiene una serie de incidencias dentro de la forma de comportamiento de las personas es descrito por Sánchez (2013):

(...) el análisis de algunas formas de evaluación presentes en la educación, señala diversas tipologías de sujetos constituidos por aquellas: ...unos conglomerados masificados, alienados, que solo se ocupan o preocupan por responder a las exigencias del mecanismo examinador. Unos individuos controlados, dominados y sometidos, unos sujetos que a fuerza de auto-percibirse -perpetuamente doblegados por tecnologías disciplinarias-, constituyen códigos de fácil control y regulación (p.759).

Este comportamiento esperado responde a parámetros sistemáticos que son forjados desde las metodologías evaluativas de un sistema.

Se vuelve una encrucijada cuando las políticas gubernamentales buscan un sistema que nivele la población estudiantil sin importar su ubicación dentro de un territorio, algo que se desarrolla bajo un discurso en favor de la equidad, pero al mismo tiempo cae en la desvalorización de la contextualización del proceso pedagógico. Cabrales (2008) señala la importancia de la contextualización insistiendo que "contextualizar es articular una realidad a otra más compleja o tratar de ajustarla a los hechos que median entre ellas para que cobre sentido y se inserte en el proceso social" (p.143). Sin embargo, dentro del sistema educativo y la evaluación, se ha desconocido, incluso ignorado, las necesidades que se enfrentan en diferentes contextos, especialmente los más rurales, y que un proceso de formación educativa debe entender. Los espacios educativos deben partir de las diferentes realidades, necesidades y particularidades del contexto en que se ejecuta para ser transformadores. Ante estos hechos, una de las áreas más afectadas y olvidadas, de manera tal vez furtiva, ha sido la investigación. A pesar de ser una de las fuentes de construcción social que brinda las primeras herramientas para el fomento de análisis y razonamientos los cuales parten de la opinión del propio individuo, la investigación ha sido dejada de lado bajo enfoques de corte más técnicos y menos constructivos en materia de conocimiento.

Otro de los principales efectos del modelo neoliberal aplicado en la región latinoamericana ha sido la reducción del estado como ente garante de la formación que recibe la ciudadanía, su debilitamiento le ha dado paso a la vez a procesos de mercantilización de la educación donde su rol responde a un comportamiento de adquisición y consumo, en donde incluso en muchas regiones la educación se vende y compra como cualquier otro servicio. En ese aspecto ha sido posible notar un proceso donde la administración educativa ha dejado de preocuparse por la formación del colectivo docente; existe poca relación entre la formación docente inicial y los procesos de capacitación continua desde el ejercicio laboral; persiste un proceso de toma de decisiones que surgen de manera sistemática y vertical en las que el personal docente solo puede obedecer; además de políticas educativas que responden al mercado y un desarrollo curricular olvidando la premisa de la investigación como eje transversal de los procesos formativos (Cardelli y Duhalde, 2001). Ante este contexto, cada docente se desenvuelve en una realidad compleja en la cual su perfil juega un papel rebajado a ser simplemente un ejecutor de programas.

Es necesario en este contexto desarrollar un análisis crítico del rol de la docencia en Latinoamérica. Esto inicia justamente por dilucidar esas dificultades que enfrenta la persona docente y la disminución de su incidencia social como un intelectual orgánico dentro de los procesos de formación pedagógica. Su rol y el de la universidad se encuentra regido incluso por parámetros internacionales como la acreditación, la cual ha surgido como una herramienta sistemática de orientación. Gurdián (2001) describe que "el debate político sobre la evaluación y la acreditación empezó a ser vigente a nivel mundial, al instaurarse el pensamiento neoliberal en la década de los ochenta" (p.14). En otras palabras, la dinámica docente se encuentra permeada 
por una serie de lineamientos que encausan su desempeño, y a la vez controlan los sistemas educativos universitarios desde una perspectiva internacional. La misma autora describe que

(...) se vislumbran propuestas de cogobierno y la tendencia de proponer un proyecto educativo global [mundial] se torna imperioso - para los impulsores de dichas propuestas-, no sólo contar con mecanismos 'de control de calidad', sino también participar en el control de los mismos sistemas (p.14).

Concluyendo en que las implicaciones de la acreditación son utilizadas como herramienta de control.

La labor del profesorado no ha sido vista como un modelo de integración donde las personas educadoras sean protagonistas de los procesos de cambio, de transición crítica, ni tampoco ha sido considerada la formación educativa como un proceso inclusivo al servicio de los sectores más populares. Además, uno de los principales problemas que se ven de manera generalizada en Latinoamérica son la falta de continuidad de las políticas implementadas a través de los Sistemas Educativos en cada país, mayoritariamente cada cambio de gobierno abandona esfuerzos e inicia con nuevas propuestas provocando descontrol y falta de claridad en la formación, el ir y venir que se enmarca en todas las estructuras sociales. Como plantean Cardelli y Duhalde (2001) el sistema educativo "adopta un enfoque vertical y autoritario, ubicando a los educadores únicamente en un papel pasivo de receptores, capacitadores y ejecutores, evitando la consulta y la participación de los educadores en el diseño y discusión de su propio plan de formación” (p.4). La labor del profesorado queda de esta forma, como se ha dicho anteriormente, reducida a la ejecución de planteamientos basados en un currículum cuyos lineamientos se hicieron en ausencia de la visión del educador. A esta realidad se suma además la precarización de las condiciones laborales del profesorado en un paradigma cada vez más complejo. Es en este contexto que la evaluación juega un proceso de grandes implicaciones sistemáticas y por tanto políticas. Ante esta realidad, es que se puede valorar a cuáles factores políticos y sociales responden las formas en las cuales se evalúa dentro de las aulas universitarias y que interés particular representa.

La evaluación es anacrónica cuando a pesar de los avances pedagógicos y tecnológicos sigue estando estancada en el tiempo. ¿Será que el comportamiento pedagógico de las personas docentes es similar debido a implicaciones políticas del sistema imperante? Cabrales (2008) sobre la evaluación describe que:

(...) implica, que a pesar de ser un mecanismo para obtener información, la evaluación no deja de verse influenciada por el acontecer en el que está inmersa. Además, si la educación constituye una práctica política, sus procesos de evaluación también lo son; por lo tanto, el contexto no deja de prescribir o trazar una perspectiva que resulta útil a la hora de desarrollar propuestas que contribuyan a evaluar los aprendizajes en la universidad (p 143).

La sociedad ha avanzado a un mundo que gira en torno a otras dinámicas y preocupaciones políticas, hay nuevos retos, pero las respuestas que se dan desde la educación formal y la pedagogía muchas veces se encuentran estáticas en el tiempo. Al inicio de este ensayo académico, se plantearon una serie de cuestionamientos en cuanto a la actualización de las formas de evaluar. Las cuales dentro de las aulas universitarias siguen siendo un reflejo de un sistema con muchas falencias, a pesar del tiempo recorrido, en la gran mayoría de casos siguen las personas estudiantes enfrentando los exámenes con preguntas dirigidas a que simplemente se transcriban en el papel lo que de memoria puedan replicar de la materia estudiada. La evaluación es anacrónica cuando su esencia es la repetición de lo que ya se sabe y la no vinculación con la construcción de nuevos conocimientos en función de un beneficio social. Es necesario plantearse nuevas formas evaluativas las cuales busquen aportes constructivos de grandes implicaciones, Mejía (2012) indica que:

Las teorías de evaluación actuales demuestran que las nuevas sociedades -del conocimiento y la información-, las condiciones sociopolíticas, los factores de desarrollo natural y las nuevas corrientes pedagógicas deben evaluarse de tal manera que adviertan la complejidad que entraña esa realidad multidimensional y multifactorial, y proponer formas holísticas, éticas y sistemáticas para valorar, estimar y enjuiciar los procesos y los productos evidentes, mediante herramientas y estrategias múltiples acordes con los modelos educativos, campos de estudio y disciplinas científicas, de forma congruente con el desarrollo humano y la prosperidad social, intentando favorecer el desempeño integral de los seres humanos y el 
desenvolvimiento en su contexto inmediato y mediato, sin olvidar que el centro de la pedagogía actual es el alumno (portador y constructor del saber) (p.31).

Planteando desde este enfoque evaluativo a la persona estudiante como centro del saber y de la acción educativa, donde a partir de un enfoque social se piensa más que un requerimiento mercantil, en una responsabilidad social.

La forma de evaluación memorística, clasista, altamente numérica y que encuadra a las personas surge como una herramienta que legitima un sistema. Gurdián (2001) recalca que "el norte o mandato internacional para las instituciones de educación superior universitaria latinoamericanas son: el mercado, la diversificación y una nueva reforma" (p.15). Dejando claro que las dinámicas de la influencia neoliberal en los sistemas educativos han estado marcadas por colocar a los procesos pedagógicos en servicio del mercado. Es innegable no solo que los sistemas educativos, incluidos los universitarios, han cedido a esta lógica, sino también a estas formas evaluativas. Procesos en función de mediciones y no de una construcción de aprendizajes, procesos que no han variado desde hace ya bastantes décadas hacia una valoración de la construcción del conocimiento y la incidencia social como único fin de todos los esfuerzos pedagógicos.

\section{ConClusión GeneraL}

Existen otras formas de evaluar que no necesariamente se concentran en clasificar con números o medir la capacidad memorística para retener información. Un ejemplo de estas valoraciones del conocimiento puede ser representado en las evaluaciones por proyectos. Donde la producción de estos puede representar la solución a una problemática social, el uso de lo teórico en función de conocimiento útil para la sociedad. Enfrentar la teoría con la realidad para que pueda ser contextualizada y depurada. Es posible la evaluación de aprendizajes bajo dinámicas de cumplimientos de objetivos o valoraciones que rijan más allá de una nota de 1 a 10. Es posible encontrar formas que contribuyan al proceso pedagógico, que no tengan como única finalidad el dar una nota o calificar un curso.

La transformación de la praxis pedagógica contempla el combatir desde el rol docente estructuras anquilosadas en el sistema educativo universitario. Representa principalmente una actitud de cambio, una actitud de enfrentar los retos y generar modificaciones que podría generar turbulencias dentro del status quo en el que se desenvuelve la realidad de las personas docentes. Es muy posible que exista resistencia, que lo más sencillo sea seguir haciendo lo mismo, pero es necesario seguir intentándolo sin dilataciones. Freire y Shor (2004) dejan claro que

(...) hay mucha presión para que se enseñe de esta forma tradicional. En primer lugar, porque es familiar y ya está funcionando, aunque no dé resultados en clase. En segundo lugar, porque, al apartarte del programa oficial, puedes ser considerado un rebelde o un disconforme, y estar sujeto a algo que puede ir desde pequeños inconvenientes hasta el despido (p.45).

Es decir, tocar ciertas estructuras incomoda lo que sistemáticamente se pretende del desempeño docente, incomoda que lo que el mercado pida de la educación universitaria no sea respondido. Sin embargo, las transformaciones sociales necesitan de un compromiso pedagógico de las personas docentes a pesar de las presiones,

Si se observa la fotografía de la evaluación hace más de 50 años podrían existir hallazgos sorprendentes. Desde la evaluación ocurre exactamente lo mismo, se siguen haciendo los mismos exámenes, las mismas preguntas y obteniendo los mismos resultados. Es en este tiempo, que urgen nuevas formas de concebir la evaluación y constituir otras formas creativas de que se analice el aprendizaje. Para esto, se ocupará de la valentía del personal docente y su humildad y esfuerzo para transformar su praxis pedagógica. Teniendo claro lo que planteaba Salazar (2006), cuando establecía que "la misma universidad es el reflejo de la sociedad, de sus actividades y de sus transformaciones" (p.32). Dejando claro que un cambio en la universidad podría a la larga generar una transformación más allá de las aulas. Es en la formación universitaria la llamada a ser rebelde 
y transformadora, que busca desde nuevos paradigmas convertirse en un instrumento con una función social más allá de las imposiciones mercantiles.

\section{ReFERENCIAS}

Cabrales, O. (2008). Contexto de la evaluación de los aprendizajes en la educación superior en Colombia: Sugerencias y alternativas para su democratización. Revista Educación y Desarrollo Social, 2(1), 141-165. doi: https://doi.o $\mathrm{rg} / 10.18359 /$

Cardelli, J., y Duhalde, M. (2001). Formación docente en América Latina una perspectiva político-pedagógica. Cuadernos de Pedagogía, 308, 38-45

Cancino, R. (2010). El modelo neoliberal y la educación universitaria en Latinoamérica: El caso de la universidad chilena. Sociedad y Discurso, 18, 145-165. doi: https://doi.org/10.5278/ojs..v0i18.881

Freire, P. (1985). La naturaleza política de la educación: cultura, poder y liberación. Barcelona, España: Paidós Ibérica

Freire, P. (1987). La educación como práctica de la libertad. Distrito Federal, México: Andrómeda

Freire, P. y Shor, I. (2004). Miedo y osadia. Buenos Aires, Argentina: Siglo XXI

Gurdián, A. (2001). Dimensión política de la evaluación y la acreditación. Revista Ciencias Sociales, 2-3(93), 11-22. Recuperado de http://www.redalyc.org/articulo.oa?id=15309302

Kaplan, M. (2009). La universidad pública: esencia, misión y crisis. Revista Mexicana de Ciencias Politicas y Sociales, 44(178), 101-133, Recuperado de http://www.redalyc.org/pdf/421/42117805.pdf

Mejía, O. (2012). De la evaluación tradicional a una nueva evaluación basada en competencias. Revista Electrónica Educare, 16(1), 27-46. Recuperado de https://bit.ly/2vBt4nE

Mora, A. (2004). La evaluación educativa: concepto, períodos y modelos. Revista Electrónica "Actualidades Investigativas en Educación", 4(2), 1-28. Recuperado de http://www.redalyc.org/pdf/447/44740211.pdf

Salazar, S. (2006). Hacia una caracterización del docente universitario "excelente": Una revisión a los aportes de la investigación sobre el desempeño del docente universitario. Revista Educación, 30(1), 31-49. Recuperado de ht tp://www.redalyc.org/pdf/440/44030103.pdf

Sánchez, T. (2013). La evaluación educativa como dispositivo de constitución de sujetos. Revista Latinoamericana de Ciencias Sociales, Niñez y Juventud, 11(2), 755-767. Recuperado de http://www.redalyc.org/pdf/773/773298 18021.pdf

\section{BY-NC-ND}

